\title{
Fear of falling is as important as multiple previous falls in terms of limiting daily activities: a longitudinal study
}

Minhui Liu ${ }^{1,2^{*}}$ (D), Tianxue Hou ${ }^{1}$, Yuxiao Li ${ }^{1}$, Xiaocao Sun ${ }^{1}$, Sarah L. Szanton ${ }^{2,3}$, Lindy Clemson ${ }^{4}$ and Patricia M. Davidson ${ }^{2}$

\begin{abstract}
Background: Fear of falling and previous falls are both risk factors that affect daily activities of older adults. However, it remains unclear whether they independently limit daily activities accounting for each other.

Methods: We used the data from Round 1 (Year 1) to Round 5 (Year 5) of the National Health and Aging Trends Study. We included a total of 864 community-dwelling participants who provided data on previous falls, fear of falling and limited activities from Year 1 to Year 5 and had no limited daily activities at Year 1 in this study. Previous falls and fear of falling were ascertained by asking participants how many falls they had in the past year and whether they had worried about falling in the last month. Limited daily activities included any difficulties with mobility (e.g., going outside), self-care (e.g., eating), and household activities (e.g., laundering). Generalized estimation equation models were used to examine whether previous falls and fear of falling independently predicted development of limited daily activities adjusting covariates.

Results: Participants were mainly between 65 and 79 years old (83\%), male (57\%), and non-Hispanic White (79\%). Among participants who had multiple falls in Year 1, 19.1-31\%, 21.4-52.4\%, and 11.9-35.7\% developed limitations in mobility, self-care, and household activities during Year 2 to Year 5, respectively. Among those who had fear of falling in Year 1, 22.5-41.3\%, 30.0-55.0 \%, and 18.8-36.3\% developed limitations in mobility, self-care, and household activities during Year 2 to Year 4, respectively. Fear of falling independently predicted limitations in mobility (Incidence rate ratio [IRR]: 1.79, $95 \% \mathrm{Cl}: 1.44,2.24)$, self-care (IRR: 1.25, $95 \% \mathrm{Cl}: 1.08,1.44$ ) and household activities (IRR: 1.39, $95 \% \mathrm{Cl}: 1.08,1.78$ ) after adjusting for previous falls and covariates. Multiple previous falls independently predicted limitations in mobility (IRR: 1.72, 1.30, 2.27), self-care (IRR: 1.40, $95 \% \mathrm{Cl}: 1.19,1.66)$ and household activities (IRR: 1.36, $95 \% \mathrm{Cl}: 1.01,1.83$ ) after adjusting fear of falling and covariates.
\end{abstract}

Conclusions: Fear of falling seems to be as important as multiple previous falls in terms of limiting older adults' daily activities.

Keywords: Fear of falling, Limited daily activities, Older adults, Previous falls

\footnotetext{
* Correspondence: mliu62@jhu.edu

${ }^{1}$ Central South University Xiangya School of Nursing, 172 Tongzipo Road of

Yuelu District, Hunan 410013 Changsha, China

2Johns Hopkins University School of Nursing, MD, Baltimore, USA

Full list of author information is available at the end of the article
} 


\section{Introduction}

About 18 million United States older adults have limited daily activities, and this number is expected to increase rapidly in the coming decades $[1,2]$. Limited daily activities arise when older adults have difficulty or need help performing daily activities. Limitations in performing daily activities are common in areas such as mobility, self-care, and household activities. For example, about $18 \%$ of United States older adults have difficulty for mobility or self-care activities, and $25 \%$ need help with household activities [2]. Limited daily activities can have adverse effects on older adults' health, and it has been a major limitation to social participation and disability [3].

Fear of falling and previous falls are two important and different predictors of limited daily activities in older adults [4-6]. Fear of falling is a persistent concern about falling, which may lead older adults to avoid activities that they are still able to do [7]. About $20-60 \%$ of community-dwelling older adults have fear of falling, and $20-55 \%$ report limited daily activities due to fear of falling [8]. About $30-50 \%$ of independently living older adults fears of falling whether or not they have previous falls [9]. In the short term, fear of falling may seem to reduce the occurrence of falls by avoiding activities, and may protect older adults from danger. For example, after an injury, fear of falling may prevent older adults from engaging in relatively dangerous activities $[10,11]$. In the long run, it may limit the ability of older adults to perform daily activities, resulting in physical function decline $[12,13]$. Studies also have shown that previous falls have adverse effects on function and loss of confidence, which may lead to limited daily activities [14]. There is a vicious cycle between fear of falling and previous falls in that they predict future falls and make future falls more likely. However, it is still unknown whether previous falls or fear of falling put more risks on limited daily activities.

Although there has been extensive research on fear of falling and previous falls as major risk factors resulting in limited daily activities, it is not clear whether fear of falling independently predicts limited activities controlling for previous falls, and vice versa from longitudinal studies. One longitudinal study found that the effects of fear of falling on declines of activities of daily living (ADLs) in non-fallers were as strong as those in fallers. However, it did not evaluate the effects of falls on declines in ADLs, and a clinical sample from a trial was used [15]. In addition, a cross-sectional study with a sample size of 251 older adults showed that compared with one previous fall, multiple previous falls may have a stronger relationship with limited daily activities [16]. However, this study limited the testing of the causal relationship between previous falls, fear of falling and limited daily activities. This could mean that multiple previous falls are a powerful predictor of limited daily activities than one previous fall. So it is important to identify their independent effects on limited daily activities because fear of falling is a psychological construct, and one or multiple falls are physical [7]. Both are modifiable but may require different types of preventive strategies $[17,18]$.

Studies have shown that sex is a risk factor for falls and fear of falling $[19,20]$. Women are more likely to fall than men, and women are more likely to have fear of falling $[19,20]$. Because of sex differences in physiological vulnerability, fear of falling as a psychological construct may differ in the predictive ability of limited daily activities depending on sex. Considering the negative impact of fear of falling on older adults, and the necessity of developing tailored interventions, it is valuable to determine whether fear of falling limits older adults' daily activities differently by sex.

The purpose of this study is to examine (1) the independent effects of one or multiple previous falls on limited daily activities adjusting for covariates and fear of falling in older adults, and (2) the independent effects of fear of falling on limited daily activities adjusting for covariates and one or multiple previous falls in older adults, and (3) whether the predictive ability of fear of falling in limited daily activities differs by sex.

\section{Methods}

The study was longitudinal, and aimed to examine whether previous falls and fear of falling independently predict limited daily activities among older adults. We used data from Year 1 to Year 5 of the National Health and Aging Trend Study (NHATS), which is a nationally representative survey of United States Medicare Beneficiaries aged 65 or older. The study was designed to investigate differences in the trajectory of various at-risk subgroups and sub-healthy older adults and deepen understanding of the gradual aging of older adults towards the end of life [21]. The data were collected in 2011 $(N=8,245)$ and then tracked annually [22]. Information on participants' physical and cognitive abilities, daily activities, and physical environment were collected via inperson interviews. The Johns Hopkins University Institutional Review Board approved the research protocol. We included a total of 864 community-dwelling participants who provided data on previous falls, fear of falling and limited activities from Year 1 to Year 5 and had no limited daily activities at Year 1 in this study. Compared to participants who were included in this study, the excluded participants, had less education, and had more chronic diseases, hospitalizations with poorer health status. The excluded participants were also less obese, engaged in less vigorous activity. 


\section{Measures}

\section{Dependent variables}

Limited daily activities included any difficulties or needing help with mobility (going outside, getting around inside, and getting in and out of bed), self-care activities (eating, bathing, toileting, and dressing), household activities (laundering, shopping, preparing meals, managing bills, and taking medications). For mobility and self-care activities, participants were asked the extent to which activities were accomplished independently in the last month, the frequency of using assistive devices to accomplish tasks last month, how often they got help from others, how much difficulty it was to independently accomplish the task, and compared to a year ago whether they accomplished the task more often, less often, or about the same. For household activities, participants were asked if anyone else had accomplished the activities with them in the last month for some reasons such as health, how difficult to accomplish the activities by themselves, and whether they accomplished activities by themselves more or less often than a year ago [2].

We classified limitations in mobility, self-care, and household activities into four levels: (1) No limitations on daily activities, which mean no use of equipment, no difficulties in activities, no need for help, or no reduction in frequency. (2) Need to use the equipment without encountering difficulties or receiving help from others. (3) Have difficulty working alone, but does not accept help from others. (4) Need help from others due to health, function, or living in nursing home [2]. Numbers of activity limitations in mobility, self-care, and household activities Participants were further classified into two groups based on these four levels: (1) No limitation in daily activities (level 1). (2) Have limitations in daily activities (level 2, 3, and 4). With these criteria, we also created variables to indicate the mean numbers of activity limitations in mobility, self-care, and household activities, respectively.

\section{Independent variables}

Previous falls were measured with the questions: "In the last 12 months, have you (or sample person, in the case of the surrogate interview) fallen down?" The answer was yes or no. "In the last 12 months, have you (or sample person, in the case of the surrogate interview) fallen down more than one time?" The answer was yes or no. A fall was defined as having a fall, trip, or slip on the floor, or lower level because of losing balance.

Fear of falling was measured by asking participants to the question: "In the last month, did you (or sample person, in the case of the surrogate interview) worry about falling down?" The responses were yes or no and we classified it as a binary variable.

\section{Covariates}

Sociodemographics Information on age group, sex, race/ethnicity, education and living arrangements were collected.

Health-related factors The BMI was calculated by dividing the current body weight in kilograms by the square of the height in meters, and obesity is defined as a BMI greater than or equal to $30 \mathrm{~kg} / \mathrm{m}^{2}$. Chronic diseases were assessed by asking participants whether doctors had diagnosed any of the following: heart attack, heart disease, high blood pressure, arthritis, osteoporosis, diabetes, lung disease, stroke, cancer and dementia/Alzheimer's disease. Hospitalizations were evaluated by asking participants if they had been hospitalized in the past year. Cognitive function was divided into three categories: no dementia, possible dementia, and probable dementia, according to the NHATS dementia classification scheme. Depression was assessed by the Patient Health Questionnaire (PHQ-2) scale.

Behavioral factors Smoking status was determined by the response to ever smoked or currently smoke cigarettes regularly, at least 1 cigarette a day. Vigorous activities were assessed by asking participants whether they ever spend time on vigorous activities that increased your heart rate and made you breathe harder in the last month (e.g., working out, swimming, running or biking, or playing a sport).

\section{Data analysis}

We first used frequencies and proportions to describe the demographic and health-related characteristics of all participants and then use Chi-square tests to compare these characteristics between those with one or multiple previous falls or without previous falls, and between those with and without fear of falling reported in Year 1. We then calculated the percentages of participants who developed limitations in mobility, self-care, and household activities at follow-ups by one or multiple previous falls and fear of falling status. We also used Chi-square tests to examine the associations between one or multiple previous falls and fear of falling in Year 1 and development of activity limitations in mobility, self-care, and household activities at follow-ups.

To investigate the independent effects of previous falls and fear of falling on development of limited daily activities, we used generalized estimating equations (GEEs) with a Poisson distribution to model the prior-wave (period $t$-1) falls or fear of falling on the probability of having limited daily activities at each current wave (period $t$ ) assessment using the log link function. GEE models are an extension of generalized 
linear models for analyzing longitudinal data accounting for the correlation of repeated measures. Using the lagged independent variables allow us to determine the temporal effects of falls and fear of falling on development of limited daily activities in this study. Independent effects of one or multiple previous falls and fear of falling were examined in three steps. First, we included one or multiple previous falls as the main predictor of each limited daily activity in the models, only adjusting for covariates (Model 1). Second, we examined fear of falling as the main predictor of limited daily activity in the model, only adjusting for covariates (Model 2). Finally, we included both one or multiple previous falls and fear of falling as predictors of each limited daily activity adjusting for covariates to examine their independent effects on limited daily activities (Model 3 ).

To examine whether the predictive ability of fear of falling in limited daily activities is different by sex, we also used GEEs with a Poisson distribution. First, we examined whether fear of falling and previous falls predicted limited daily activities stratified by sex as a binary variable (namely strategy analysis). Then, we tested the significance of the interaction term between fear of falling and sex, and the interaction term between previous falls and sex using models described above (namely analysis with interaction terms).

Since missing values on covariate variables were less than $1.6 \%$, we did not apply any techniques to handle them. All analyses were performed using Stata version 14.0 (Stata Corp, College Station, Texas, USA); $p<.05$ (two-tailed) was used to indicate statistical significance. Incidence rate ratios (IRRs) and $95 \%$ confidence intervals (CIs) were reported from GEE models.

\section{Results}

\section{Sample characteristics}

The participants without limited daily activities in Year 1 were mostly aged between 65 and 79 years old. About $57 \%$ were male, $60 \%$ received some college education or higher, the majority were nonHispanic White $(79 \%)$, and about $26 \%$ lived alone. They were generally healthy, with only about $23 \%$ being obese, $8 \%$ ever smoked, $18 \%$ having none chronic condition, $88 \%$ not hospitalized in last year, and about half performing vigorous activities in the last year. About 18 and $9 \%$ of participants had previous falls and fear of falling in Year 1, respectively. Participants who fell last year were more likely to be female and have a smoking history. Those who had fear of falling tended to be older females and with 3 or more chronic conditions (Table 1).
Association of Year 1 previous falls, Year 1 fear of falling (fear of falling), and development of limited daily activities from Year 2 to Year 5

Figure 1 shows the percentage of participants who developed limited daily activities from Year 2 to Year 5 by previous falls and fear of falling status at Year 1 . Overall, among participants with reported one or multiple previous falls or fear of falling at Year 1, the percentages of developing limitations in mobility, selfcare, and household activities steadily increased from Year 2 to Year 5. For example, among participants who reported a fall at Year 1, 11.1-25.9\% developed limitations in mobility, 31.5-51.9\% experienced limitations in self-care activities, and 20.4-34.3\% had household limited daily activities during follow-ups Year 2 to Year 5. Year 1 multiple previous falls were only significantly associated with a higher percentage of participants who had limitations in self-care activities in Year 4. However, Year 1 fear of falling significantly contributed to developing limitations in mobility, self-care, and household activities in the following years. For example, participants who had fear of falling in Year 1 were more likely to have limitations in mobility since Year 2 and limitations in selfcare activities since Year 3 (Fig. 1).

\section{Independent effects of previous falls and fear of falling on limited daily activities}

Table 2 summarizes incidence rate ratio estimates of limited daily activities adjusting for covariates from GEE models. Model 1 and Model 2 showed that both multiple previous falls and fear of falling in the prior year independently predicted development of limitations in mobility, self-care, and household activities a year later after adjusting for covariates. For example, the incidence rate of mobility limitations was 1.96 times greater among those who had multiple times last year compared to those without previous falls (IRR: 1.96, $95 \%$ CI: 1.49, 2.59). Participants who had fear of falling in the prior year also had a significant higher incidence of mobility limitations compared to those without fear of falling (IRR: 1.93, $95 \%$ CI: 1.54, 2.40). After including both previous falls and fear of falling in the adjusted models, multiple previous falls (IRR: 1.72, 1.30, 2.27) and fear of falling (IRR: 1.79, $95 \%$ CI: 1.44, 2.44) still independently predicted subsequent mobility limitations; which was also true for limitations in self-care activities (IRR: 1.40, $95 \%$ CI: 1.19, 1.66) vs. (IRR: 1.25 , $95 \%$ CI: 1.08, 1.44), and household activities (IRR: 1.36, $95 \%$ CI: 1.01, 1.83) vs. (IRR: 1.39, $95 \%$ CI: $1.08,1.78)$. 
Table 1 Sample characteristics by previous falls and fear of falling status in Year 1 ( $n, \%)$

\begin{tabular}{|c|c|c|c|c|c|c|c|c|}
\hline \multirow[t]{2}{*}{ Variables } & \multirow[t]{2}{*}{ All } & \multicolumn{4}{|c|}{ Previous Falls in Year 1} & \multicolumn{3}{|c|}{ Fear of Falling in Year 1} \\
\hline & & No & One fall & Multiple falls & $P$ value & No & Yes & $P$ value \\
\hline Age (y) & & & & & 0.238 & & & 0.039 \\
\hline $65-79$ & $719(83.2)$ & $588(81.8)$ & $96(13.4)$ & $35(4.9)$ & & $659(91.7)$ & $60(8.3)$ & \\
\hline $80-90+$ & $145(16.8)$ & $126(86.9)$ & $12(8.3)$ & $7(4.8)$ & & $125(86.2)$ & $20(13.8)$ & \\
\hline Sex & & & & & 0.106 & & & 0.012 \\
\hline Female & $371(42.9)$ & $295(79.5)$ & $54(14.6)$ & $22(5.9)$ & & $326(87.9)$ & $45(12.1)$ & \\
\hline Male & $493(57.1)$ & $419(85.0)$ & $54(11.0)$ & $20(4.1)$ & & $458(92.9)$ & $35(7.1)$ & \\
\hline Education & & & & & 0.104 & & & 0.180 \\
\hline Less than high school & $133(15.5)$ & $106(79.7)$ & $20(15.0)$ & $7(5.3)$ & & $125(94.0)$ & $8(6.0)$ & \\
\hline High school graduates & $209(24.3)$ & $173(82.8)$ & $32(15.3)$ & $4(1.91)$ & & $184(88.0)$ & $25(12.0)$ & \\
\hline Some college or vocational school & $195(22.7)$ & $169(86.7)$ & $16(8.2)$ & $10(5.1)$ & & $174(89.2)$ & $21(10.8)$ & \\
\hline Bachelor or higher & $322(37.5)$ & $262(81.4)$ & $40(12.4)$ & $20(6.2)$ & & $297(92.2)$ & $25(7.8)$ & \\
\hline Race & & & & & 0.079 & & & 0.083 \\
\hline White, non-Hispanic & $683(79.1)$ & $562(82.3)$ & $84(12.3)$ & $37(5.4)$ & & $618(90.5)$ & $65(9.5)$ & \\
\hline Black, non-Hispanic & $127(14.7)$ & $111(87.4)$ & $14(11.0)$ & $2(1.6)$ & & $121(95.3)$ & $6(4.7)$ & \\
\hline Hispanic & $30(3.5)$ & $23(76.7)$ & $7(23.3)$ & 0 & & $25(83.3)$ & $5(16.7)$ & \\
\hline Indian/Asian/Native/Hawaii/Other & $24(2.8)$ & $18(75.0)$ & $3(12.5)$ & $3(12.5)$ & & $20(83.3)$ & $4(16.7)$ & \\
\hline Living & & & & & 0.435 & & & 0.317 \\
\hline Alone & $220(25.6)$ & $182(82.7)$ & $29(13.2)$ & $9(4.1)$ & & $197(89.6)$ & $23(10.5)$ & \\
\hline With spouse/partner only & $482(56.1)$ & $394(81.7)$ & $62(12.9)$ & $26(5.4)$ & & $442(91.7)$ & $40(8.3)$ & \\
\hline With others only & $77(9.0)$ & $61(79.2)$ & $10(13.0)$ & $6(7.8)$ & & $66(85.7)$ & $11(14.3)$ & \\
\hline With spouse/partner and with others & $81(9.4)$ & $73(90.1)$ & $7(8.6)$ & $1(1.2)$ & & $75(92.6)$ & $6(7.4)$ & \\
\hline BMI & & & & & 0.619 & & & 0.123 \\
\hline Normal & $660(77.5)$ & $542(82.1)$ & $85(12.9)$ & $33(5.0)$ & & $605(91.7)$ & $55(8.3)$ & \\
\hline Obesity & $192(22.5)$ & $163(84.9)$ & $22(11.5)$ & $7(3.7)$ & & $169(88.0)$ & $23(12.0)$ & \\
\hline Smoking & & & & & 0.046 & & & 0.572 \\
\hline No & $796(92.1)$ & $664(83.2)$ & $93(11.7)$ & $39(4.9)$ & & 721 (90.6) & $75(9.4)$ & \\
\hline Yes & $68(7.9)$ & $50(73.5)$ & $15(22.1)$ & $3(4.4)$ & & $63(92.7)$ & $5(7.4)$ & \\
\hline Vigorous activities & & & & & 0.643 & & & 0.179 \\
\hline No & $392(45.4)$ & $321(81.9)$ & $49(12.5)$ & $22(5.6)$ & & $350(89.3)$ & $42(10.7)$ & \\
\hline Yes & $472(54.6)$ & $393(83.3)$ & $59(12.5)$ & $20(4.2)$ & & $434(92.0)$ & $38(8.1)$ & \\
\hline Number of chronic illnesses & & & & & 0.334 & & & 0.043 \\
\hline No disease & $157(18.2)$ & $135(86.0)$ & $14(8.9)$ & $8(5.1)$ & & $149(94.9)$ & $8(5.1)$ & \\
\hline $1 \sim 3$ & $601(69.6)$ & $493(82.0)$ & $82(13.6)$ & $26(4.3)$ & & $544(90.5)$ & $57(9.5)$ & \\
\hline$\geq 4$ & $106(12.3)$ & $86(81.1)$ & $12(11.3)$ & $8(7.6)$ & & $91(85.9)$ & $15(14.2)$ & \\
\hline Hospitalization & & & & & 0.213 & & & 0.872 \\
\hline No hospitalization & $762(88.2)$ & $636(83.5)$ & $91(11.9)$ & $35(4.6)$ & & $691(90.7)$ & $71(9.3)$ & \\
\hline At least one hospitalization & $102(11.8)$ & $78(76.5)$ & $17(16.7)$ & $7(6.9)$ & & $93(91.2)$ & $9(8.8)$ & \\
\hline Depression & & & & & 0.006 & & & 0.292 \\
\hline No depression & 809 (93.9) & $676(83.6)$ & $93(11.5)$ & $40(4.9)$ & & $737(91.1)$ & $72(8.9)$ & \\
\hline Depression & $53(6.2)$ & $37(69.8)$ & $14(26.4)$ & $2(3.8)$ & & $46(86.8)$ & $7(13.2)$ & \\
\hline Cognitive function & & & & & 0.877 & & & 0.339 \\
\hline No dementia & $789(91.3)$ & $650(82.4)$ & $99(12.6)$ & $40(5.1)$ & & 718 (91) & $71(9)$ & \\
\hline Possible dementia & $60(6.9)$ & $51(85)$ & $7(11.7)$ & $2(3.33)$ & & $54(90)$ & $6(10)$ & \\
\hline Probable dementia & $15(1.7)$ & $13(86.7)$ & $2(13.3)$ & 0 & & $12(80)$ & $3(20)$ & \\
\hline
\end{tabular}



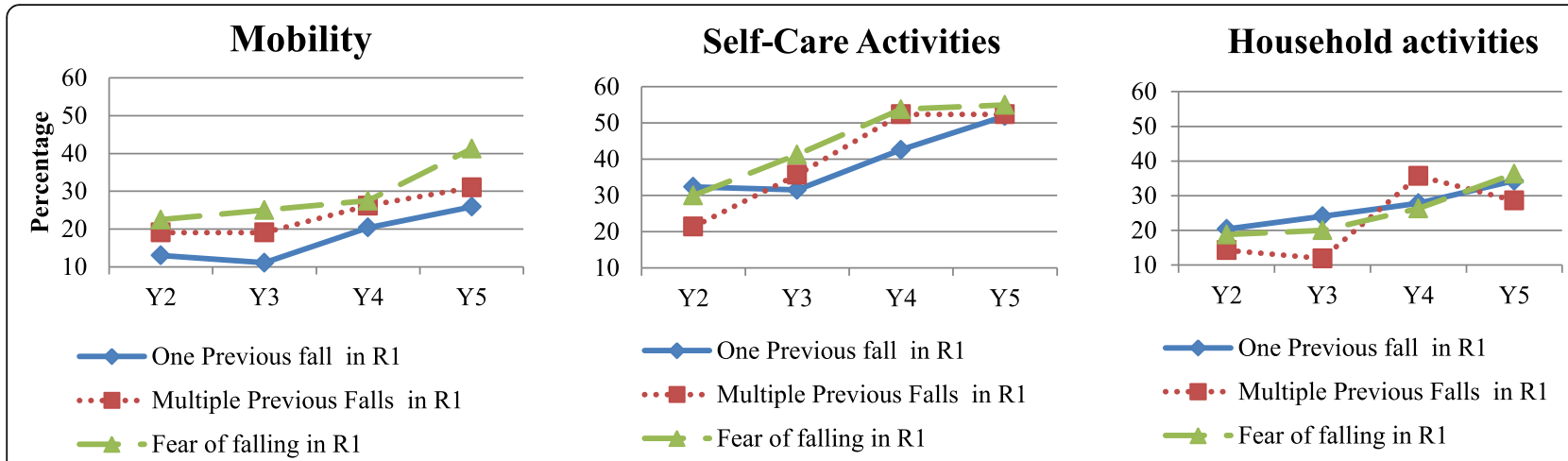

Fig 1. Percentages of participants who developed activity limitations from Year 2 to Year 5

\section{Predicting ability of fear of falling in developing activity limitations differed by sex}

Table 3 summarizes incidence rate ratio estimates of limited daily activities by sex adjusting for covariates from GEE models. The stratified analysis showed that fear of falling in the prior year independently predicted development of limitations in mobility (IRR: 2.07, $95 \%$ CI: $1.58,2.71$ ), self-care (IRR: $1.50,95 \%$ CI: 1.24, 1.81), and household activities (IRR: $2.10,95 \%$ CI: 1.60, 2.76) a year later, and multiple previous falls independently predicted development of limitations in mobility (IRR: 1.67, $95 \%$ CI: $1.14,2.45$ ) and self-care activities (IRR: 1.49, $95 \%$ CI: $1.22,1.82$ ) a year later among men after adjusting for covariates. Multiple previous falls in the prior year independently predicted development of limitations in mobility (IRR: 1.83 , $95 \%$ CI: $1.23,2.74$ ), and household activities (IRR: 1.56, 95 \% CI: 1.05, 2.32) a year later among women after adjusting for covariates. The analysis with interaction terms showed the similar results, that fear of falling play a more severe role as a predictor on self-care, and household activities in men then in women.

\section{Discussion}

Using a nationally representative sample of communitydwelling older adults, this study examined the independent effects of fear of falling on development of limited daily activities adjusting for covariates and previous falls, and vice versa. The prevalence rates of previous falls and fear of falling in Year 1 of this study were 18 and $9 \%$, respectively. These rates were lower than those of previous studies in which fall rates ranged from 29 to $45 \%$ and fear of falling rates ranged from 20 to $60 \%$ [16, 23-27]. This is expected as we excluded participants with limited daily activities in Year 1 for the study purpose.

Table 2 Independent effects of previous falls and fear of falling on limited daily activities

\begin{tabular}{|c|c|c|c|}
\hline Variables & $\begin{array}{l}\text { Model } 1 \\
\text { IRR }[95 \% \mathrm{Cl}]\end{array}$ & $\begin{array}{l}\text { Model } 2 \\
\text { IRR }[95 \% \mathrm{CI}]\end{array}$ & $\begin{array}{l}\text { Model } 3 \\
\text { IRR }[95 \% \mathrm{CI}]\end{array}$ \\
\hline \multicolumn{4}{|l|}{ Mobility } \\
\hline One Fall & $1.14[0.91,1.44]$ & & $1.09[0.87,1.36]$ \\
\hline Multiple Falls & $1.96[1.49,2.59]^{* * *}$ & & $1.72[1.30,2.27]^{* * *}$ \\
\hline Fear of Falling & & $1.93[1.54,2.40]^{* * *}$ & $1.79[1.44,2.24]^{* * *}$ \\
\hline \multicolumn{4}{|l|}{ Self-care activities } \\
\hline One Fall & $0.97[0.85,1.10]$ & & $0.95[0.84,1.08]$ \\
\hline Multiple Falls & $1.47[1.25,1.74]^{* * *}$ & & $1.40[1.19,1.66]^{* * *}$ \\
\hline Fear of Falling & & $1.31[1.14,1.51]^{* * *}$ & $1.25[1.08,1.44]^{* * *}$ \\
\hline \multicolumn{4}{|c|}{ Household activities } \\
\hline One Fall & $1.17[0.94,1.46]$ & & $1.13[0.91,1.41]$ \\
\hline Multiple Falls & $1.48[1.11,1.98]^{* *}$ & & $1.36[1.01,1.83]^{*}$ \\
\hline Fear of Falling & & $1.46[1.14,1.87]^{* *}$ & $1.39[1.08,1.78]^{*}$ \\
\hline
\end{tabular}

* IRR incidence rate ratio; ${ }^{*} p<.05,{ }^{* *} p<.01,{ }^{* * *} p<.001$

All models adjusted for demographic covariates (age, sex, education, race/ethnicity, living arrangement), health-related covariates (BMI, number of chronic illnesses, hospitalizations, depression, cognitive function), and behavioral covariates (smoking and vigorous activities) 
Table 3 Independent and interaction effects of previous falls and fear of falling on developing activity limitations by sex

\begin{tabular}{|c|c|c|c|}
\hline \multirow[t]{2}{*}{ Variables } & \multicolumn{2}{|l|}{$\begin{array}{l}\text { Stratified Analysis } \\
\text { IRR }[95 \% \mathrm{Cl}]\end{array}$} & \multirow[t]{2}{*}{$\begin{array}{l}\text { Analysis with Interaction Term } \\
\text { IRR }[95 \% \mathrm{Cl}]\end{array}$} \\
\hline & Male & Female & \\
\hline \multicolumn{4}{|l|}{ Mobility } \\
\hline One Fall & $1.24[0.92,1.67]$ & $0.88[0.62,1.25]$ & $1.09[0.87,1.37]$ \\
\hline Multiple Falls & $1.67[1.14,2.45]^{* *}$ & $1.83[1.23,2.74]^{* *}$ & $1.72[1.30,2.28]^{* * *}$ \\
\hline Fear of Falling & $2.07[1.58,2.71]^{* * *}$ & $1.59[1.10,2.30]^{*}$ & $1.53[1.07,2.18]^{*}$ \\
\hline Fear of Falling*Sex & & & $1.33[0.86,2.04]$ \\
\hline \multicolumn{4}{|l|}{ Self-care activities } \\
\hline One Fall & $0.95[0.79,1.13]$ & $0.96[0.80,1.16]$ & $0.96[0.84,1.09]$ \\
\hline Multiple Falls & $1.49[1.22,1.82]^{* * *}$ & $1.27[0.96,1.68]$ & $1.40[1.19,1.66]^{* * *}$ \\
\hline Fear of Falling & $1.50[1.24,1.81]^{* * *}$ & $1.05[0.87,1.28]$ & $1.01[0.84,1.22]$ \\
\hline Fear of Falling*Sex & & & $1.50[1.16,1.94]^{* *}$ \\
\hline \multicolumn{4}{|l|}{ Household activities } \\
\hline One Fall & $1.32[0.98,1.77]$ & $1.00[0.74,1.36]$ & $1.15[0.93,1.42]$ \\
\hline Multiple Falls & $1.29[0.84,1.98]$ & $1.56[1.05,2.32]^{*}$ & $1.39[1.03,1.86]^{*}$ \\
\hline Fear of Falling & $2.10[1.60,2.76]^{* * *}$ & $0.98[0.67,1.44]$ & $0.90[0.62,1.32]$ \\
\hline Fear of Falling*Sex & & & $2.36[1.51,3.71]^{* * *}$ \\
\hline
\end{tabular}

* IRR incidence rate ratio; ${ }^{*} p<.05,{ }^{* *} p<.01,{ }^{* * *} p<.001$

Stratified analysis: demographic covariates (age, education, race/ethnicity, living arrangement), health-related covariates (BMI, number of chronic illnesses, hospitalizations, depression, cognitive function), and behavioral covariates (smoking and vigorous activities)

Analysis with interaction terms: demographic covariates (age, sex education, race/ethnicity, living arrangement), health-related covariates (BMI, number of chronic illnesses, hospitalizations, depression, cognitive function), and behavioral covariates (smoking and vigorous activities)

Our study found that multiple previous falls and fear of falling have the same predictive ability for limited daily activities, but one previous fall was not. Study has shown that the association between fear of falling and activity avoidance is affected by the number of falls in the past year. But older adults who had not experienced a fall also showed limited daily activities. This suggested that some significant portion of fear of falling was inappropriate [16]. Excessive fear of falling can have a major impact on physical performance and lead to poor balance [28, 29]. Delbaere et al. showed that previous falls do not directly lead to changes in daily behaviors, but effective-cognitive variables associated with falls, such as a concern about falling during activity, can mediate this process [30]. Further their modelling also supported that catastrophic fear of falling, such as fear of hip fracture or institutionalization, can lead to activity and mobility restriction without previous falls. Thus, fear of falling as an affective-cognitive variable, whether a worry about falls or a fear of falling, is an important influencing factor leading to changes in daily activities. In some older adults with impaired mobility, fear of falling may result in ADLs impairments, depression, and disability [31-34]. On this basis, our research adds to previous research findings, recognizing that fear of falling can be as important as multiple previous falls in limited daily activities of older adults. Studies have shown that fear of falling can be alleviated by improving cognitive behavior and daily activities in older adults [35, 36]. For older adults who have fear of falling, it might act as barrier for up-taking any fall prevention study or intervention, so lifestyle changes are recommended to achieve effective intervention [37]. At the same time, we should also pay attention to older adults with multiple previous falls to improve their physical fitness and reduce the incidence of falls.

In our study, fear of falling is more predictive of limited daily activities among men than women. In the previous literature, sex is a risk factor of fear of falling, but most of the studies are cross-sectional studies [20,38]. Friedman and colleagues found that factors such as women, older age, and self-reported previous fall within the last year, are related to the development of fear of falling [27]. Our research results were different from previous studies, which may be because our sample size is mostly male after excluding participants who had limited daily activities in Year 1 .

One strength of this study is that we used a nationally representative longitudinal dataset that allows us to examine the temporal effects of previous falls and fear of falling on the development of limited daily activities. A comprehensive list of covariates were assessed and adjusted for in this study and this allows to provide relatively robust findings. However, there are also some limitations to this study. First, fear of falling was measured by a single item asking if they were worried about 
falling for which the reliability and validity are still unknown. However, this measure has been widely used in cohort studies and showed consistent findings on health outcomes. Second, recall bias might occur when asking participants about fall experience. We used previous falls as a binary variable instead of a continuous variable, which may lessen the threat to the robustness of our findings. Third, our sample is relatively small after excluding those who missed for follow-ups and had limited daily activities in Year 1, therefore, our study results mainly apply to predominantly healthy and physically active older adults. Yet, fear of falling could have a less relevant influence on daily activities in subjects presenting with a higher number and severity of comorbidities, which may have a greater impact than fear of falling on individuals' autonomy.

\section{Conclusions}

In summary, while both previous falls and fear of falling are important predictors of limitations in performing daily activities, multiple previous falls and fear of falling make equivalent adverse impact on developing limitations in major daily activities. While paying attention to the fall experience of older adults, we should develop and apply useful strategies to reduce fear of falling among older adults in order to improve their ability to perform daily activities and stay physically independent, and prevent falls.

\section{Abbreviations \\ ADLs: Activities of Daily Living; NHATS: National Health and Aging Trends Study; GEE: Generalized Estimating Equations; IRR: Incidence rate ratio; BMI: Body Mass Index; Cl: Confidence Interval}

\section{Acknowledgements}

None.

\section{Authors' contributions}

ML: study concept and design, acquisition of data, and analysis, interpretation of data, final approval of version to be published. TH: drafting of the manuscript, critical revision of the manuscript for important intellectual content. YL, XS, SLS, PMD, LC: critical revision of the manuscript for important intellectual content. ML: The author(s) read and approved the final manuscript.

\section{Funding}

None.

\section{Availability of data and materials}

The NHATS data analyzed in the current study are available for research purposes at www.nhats.org.

\section{Declarations}

\section{Ethics approval and consent to participate}

This is a secondary data analysis study using the National Health and Aging Trends Study database which is a publicly available to researchers and does not require access permission. The National Health and Aging Trends Study was approved by the Johns Hopkins University Institutional Review Board. The current analyses were deemed exempt by the Johns Hopkins School of Medicine.
Consent for publication

Not applicable.

\section{Competing interests}

The authors declare that they have no competing interests.

\section{Author details}

${ }^{1}$ Central South University Xiangya School of Nursing, 172 Tongzipo Road of

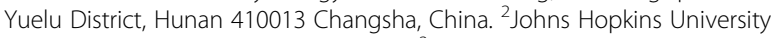
School of Nursing, MD, Baltimore, USA. ${ }^{3}$ Johns Hopkins University Bloomberg School of Public Health, MD, Baltimore, USA. ${ }^{4}$ The University of Sydney, New South Wales, Camperdown, Australia.

Received: 17 October 2020 Accepted: 27 May 2021

Published online: 07 June 2021

\section{References}

1. Han SH, Kim K, Burr JA. Activity limitations and depressive symptoms among older couples: the moderating role of spousal care [published online Dec 28 2019]. J Gerontol B-Psychol. 2019. doi:https://doi.org/10.1093/geronb/gbz161.

2. Freedman VA, Spillman BC. Disability and care needs among older Americans. Milbank Q. 2014;92(3):509-41.

3. Wolf D. Late-life disability trends and trajectories. In: Handbook of aging and the social sciences. 8th ed. USA: Elsevier; 2016. p. 77-99.

4. Denkinger MD, Lukas A, Nikolaus T, Hauer K. Factors associated with fear of falling and associated activity restriction in community-dwelling older adults: a systematic review. Am J Geriat Psychiat. 2015;23(1):72-86.

5. Deandrea S, Bravi F, Turati F, Lucenteforte E, Vecchia CA, Negri E. Risk factors for falls in older people in nursing homes and hospitals. A systematic review and meta-analysis. Arch Gerontol Geriatr. 2013;56(3):407-15.

6. Castaldo A, Giordano A, Antonelli Incalzi R, Lusignani M. Risk factors associated with accidental falls among Italian nursing home residents: a longitudinal study (FRAILS). Geriatr Nurs. 2020;41(2):75-80.

7. Tinetti ME, Richman D, Powell L. Falls efficacy as a measure of fear of falling. J Gerontol. 1990;45(6):P239-43.

8. van Haastregt JC, Zijlstra GA, van Rossum E, van Eijk JT, de Witte LP, Kempen Gl. Feasibility of a cognitive behavioural group intervention to reduce fear of falling and associated avoidance of activity in communityliving older people: a process evaluation. BMC Health Serv Res. 2007;7:156

9. Binda SM, Culham EG, Brouwer B. Balance, muscle strength, and fear of falling in older adults. Exp Aging Res. 2003;29(2):205-19.

10. Delbaere K, Crombez G, Vanderstraeten G, Willems T, Cambier D. Fearrelated avoidance of activities, falls and physical frailty. A prospective community-based cohort study. Age Ageing. 2004;33(4):368-73.

11. Adamczewska N, Nyman SR. A new approach to fear of falls from connections with the posttraumatic stress disorder literature. Gerontol Geriatr Med. 2018:4:2333721418796238-8.

12. Zijlstra G, Van Haastregt J, Van Eijk JTM, van Rossum E, Stalenhoef PA, Kempen GI. Prevalence and correlates of fear of falling, and associated avoidance of activity in the general population of community-living older people. Age Ageing. 2007;36(3):304-9.

13. Rivasi G, Kenny RA, Ungar A, Romero-Ortuno R. Predictors of incident fear of falling in community-dwelling older adults. J Am Med Dir Assoc. 2020;21(5): 615-20

14. Batchelor FA, Hill KD, Mackintosh SF, Said CM, Whitehead CH. The FLASSH study: protocol for a randomised controlled trial evaluating falls prevention after stroke and two sub-studies. BMC Neurol. 2009;9(1):14-22.

15. Cumming RG, Salkeld G, Thomas M, Szonyi G. Prospective study of the impact of fear of falling on activities of daily living, SF-36 scores, and nursing home admission. J Gerontol A Biol Sci Med Sci. 2000;55(5):M299-305.

16. Bertera EM, Bertera RL. Fear of falling and activity avoidance in a national sample of older adults in the United States. Health Soc Work. 2008;33(1):54-62.

17. Scheffer AC, Schuurmans MJ, Van Dijk N, Van Der Hooft T, De Rooij SE. Fear of falling: measurement strategy, prevalence, risk factors and consequences among older persons. Age Ageing. 2008;37(1):19-24.

18. Murphy SL, Dubin JA, Gill TM. The development of fear of falling among community-living older women: predisposing factors and subsequent fall events. J Gerontol A-Biol. 2003;58(10):M943-7.

19. Yamashita T, Noe DA, Bailer AJ. Risk factors of falls in community-dwelling older adults: logistic regression tree analysis. Gerontologist. 2012;52(6):822-32. 
20. Howland J, Lachman ME, Peterson EW, Cote J, Kasten L, Jette A. Covariates of fear of falling and associated activity curtailment. Gerontologist. 1998; 38(5):549-55.

21. Freedman VA, Kasper JD. Cohort Profile: The National Health and Aging Trends Study (NHATS). Int J Epidemiol. 2019;48(4):1044-5g.

22. Stephan $Y$, Sutin $A R$, Luchetti $M$, Terracciano A. Subjective age and risk of incident dementia: evidence from the National Health and Aging Trends survey. J Psychiatr Res. 2018;100:1-4.

23. Lach HW. Incidence and risk factors for developing fear of falling in older adults. Public Health Nurs. 2005;22(1):45-52.

24. Arfken CL, Lach HW, Birge SJ, Miller JP. The prevalence and correlates of fear of falling in elderly persons living in the community. Am J Public Health. 1994;84(4):565-70.

25. Soriano TA, DeCherrie LV, Thomas DC. Falls in the community-dwelling older adult: a review for primary-care providers. Clin Interv Aging. 2007:2(4):545-54

26. Bergen $G$, Stevens MR, Burns ER. Falls and fall injuries among adults aged $\geq 65$ years - United States, 2014. MMWR Morb Mortal Wkly Rep. 2016;65(37):993-8

27. Friedman SM, Munoz B, West SK, Rubin GS, Fried LP. Falls and fear of falling: which comes first? A longitudinal prediction model suggests strategies for primary and secondary prevention. J Am Geriatr Soc. 2002;50(8):1329-35.

28. Deshpande N, Metter EJ, Lauretani F, Bandinelli S, Guralnik J, Ferrucci L. Activity restriction induced by fear of falling and objective and subjective measures of physical function: a prospective cohort study. J Am Geriatr Soc. 2008:56(4):615-20.

29. Delbaere K, Crombez G, Van Den Noortgate N, Willems T, Cambier D. The risk of being fearful or fearless of falls in older people: an empirical validation. Disabil Rehabil. 2006;28(12):751-6.

30. Delbaere K, Crombez G, van Haastregt JC, Vlaeyen JW. Falls and catastrophic thoughts about falls predict mobility restriction in community-dwelling older people: a structural equation modelling approach. Aging Ment Health. 2009;13(4):587-92.

31. Suzuki M, Ohyama N, Yamada K, Kanamori M. The relationship between fear of falling, activities of daily living and quality of life among elderly individuals. Nurs Health Sci. 2002:4(4):155-61.

32. Auais $M$, French $S$, Alvarado B, Pirkle C, Belanger E, Guralnik J. Fear of falling predicts incidence of functional disability 2 years later: a perspective from an international cohort study. J Gerontol A-Biol. 2018;73(9):1212-5.

33. Vellas BJ, Wayne SJ, Romero LJ, Baumgartner RN, Garry PJ. Fear of falling and restriction of mobility in elderly fallers. Age Ageing. 1997;26(3):189-93.

34. Viljanen A, Kulmala J, Rantakokko M, Koskenvuo M, Kaprio J, Rantanen T. Fear of falling and coexisting sensory difficulties as predictors of mobility decline in older women. J Gerontol A-Biol. 2012;67(11):1230-7.

35. Finch TL, Bamford C, Deary V, Sabin N, Parry SW. Making sense of a cognitive behavioural therapy intervention for fear of falling: qualitative study of intervention development. BMC Health Serv Res. 2014;14(1):436-47.

36. Sakurai R, Fujiwara Y, Yasunaga M, et al. Association between hypometabolism in the supplementary motor area and fear of falling in older adults. Front Aging Neurosci. 2017;9:251-8.

37. Clemson L, Kendig H, Mackenzie L, Browning C. Predictors of injurious falls and fear of falling differ: an 11-year longitudinal study of incident events in older people. J Aging Health. 2015;27(2):239-56.

38. Fessel KD, Nevitt MC. Correlates of fear of falling and activity limitation among persons with rheumatoid arthritis. Arthritis Care Res. 1997;10(4):222-8.

\section{Publisher's Note}

Springer Nature remains neutral with regard to jurisdictional claims in published maps and institutional affiliations.

Ready to submit your research? Choose BMC and benefit from:
- fast, convenient online submission
- thorough peer review by experienced researchers in your field
- rapid publication on acceptance
- support for research data, including large and complex data types
- gold Open Access which fosters wider collaboration and increased citations
- maximum visibility for your research: over 100M website views per year
At BMC, research is always in progress.
Learn more biomedcentral.com/submissions

